\title{
Is The Allergen Really Needed in Allergy Immunotherapy?
}

Thomas M. Kündig, M.D. ${ }^{1, *}$

Ludger Klimek, M.D. ${ }^{2}$

Philipp Schendzielorz, M.D. ${ }^{2}$

Wolfgang A. Renner, Ph.D. ${ }^{3}$

Gabriela Senti, M.D. ${ }^{4}$

Martin F. Bachmann, Ph.D. ${ }^{1,5}$

\author{
Address \\ *,1Dermatology Department, Zurich University Hospital, Gloriastr. 31, 8091, \\ Zurich, Switzerland \\ Email: thomas.kuendig@usz.ch \\ 'Zentrum für Rhinologie und Allergologie, Wiesbaden, Germany \\ ${ }^{3}$ AREBA Biotech AG, Kilchberg, Switzerland \\ ${ }^{4}$ Center for Clinical Trials, Zürich, Switzerland \\ ${ }^{5}$ National Center for Cancer Care and Research, Hamad Medical Corporation, Doha, \\ Qatar \\ Published online: 6 December 2014 \\ (C) The Author(s) 2014. This article is published with open access at Springerlink.com
}

This article is part of the Topical Collection on Specific Immunotherapy

Keywords Virus-like particles · CpG motifs • Vaccine • Allergy • Allergic rhinitis · Immunotherapy

\section{Opinion Statement}

Immunotherapy for type I allergies is well established and is regarded to be the most efficient treatment option besides allergen avoidance. As of today, different forms of allergen preparations are used in this regard, as well as different routes of application. Virus-like particles (VLPs) represent a potent vaccine platform with proven immunogenicity and clinical efficacy. The addition of toll-like receptor ligands and/or depot-forming adjuvants further enhances activation of innate as well as adaptive immune responses. CPG motifs represent intensively investigated and potent direct stimulators of plasmacytoid dendritic cells and B cells, while $T$ cell responses are enhanced indirectly through increased antigen presentation and cytokine release. This article will focus on the function of VLPs loaded with DNA rich in nonmethylated CG motifs (CpGs) and the clinical experience gained in the treatment of allergic rhinitis, demonstrating clinical efficacy also if administered without allergens. Several published studies have demonstrated a beneficial impact on allergic symptoms by treatment with CpG-loaded VLPs. Subcutaneous injection of VLPs loaded with CpGs was tested with or without the adjuvant alum in the presence or absence of an allergen. The results encourage further investigation of VLPs and $\mathrm{CpG}$ motifs in immunotherapy, either as a stand-alone product or as adjuvants for allergen-specific immunotherapy. 


\section{Introduction}

Respiratory allergies today are some of the most prevalent chronic diseases [1]. According to the Allergic Rhinitis and its Impact on Asthma (ARIA) Initiative, allergic rhinitis is defined as immunoglobulin (Ig)-E-mediated inflammation of the nasal mucosa with the respective symptoms upon allergen exposure [2]. Apart from allergen avoidance, allergy immunotherapy (AIT) represents the only causative treatment option [3-6].

Allergen-specific immunotherapy over 3-5 years requires numerous allergen applications either subcutaneously or sublingually $[7,8]$, leading to symptom amelioration, reduced use of medication, and better quality of life [3-6]. Importantly, allergen-specific immunotherapy has long-term effects $[9,10]$ and is disease modifying, as it can prevent the progression of rhinitis to asthma [1113]. Despite all of these medical advantages over symptomatic pharmacotherapy, fewer than $5 \%$ of allergy patients choose to get treated with AIT [14-16]. This is mainly because of two disadvantages of current AIT protocols. The first disadvantage is that the numerous injections and visits to a medical office over years are very time consuming for the patient. The second disadvantage is that allergen injection is often associated with adverse reactions, which are typically harmless and not bothersome injection site reactions in subcutaneous immuno- therapy (SCIT) and oral or gastrointestinal symptoms in sublingual immunotherapy (SLIT); these are experienced by the majority of patients, but adverse events in rare cases may also range from severe systemic allergic reactions to anaphylaxis [17]. Various novel strategies have been proposed to enhance the efficacy and shorten the course of therapy in order to also enhance its safety. These strategies include the use of recombinant native major allergens, as well as modified hypoallergenic allergens [18], use of allergen-derived peptides representing CD4 T cell epitopes $[19,20,21 \bullet \bullet]$, intralymphatic immuno-

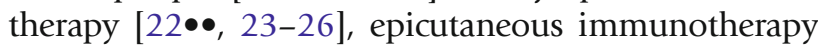
$[27-34,35 \bullet \bullet, 36]$, and also the use of adjuvants more potent than alum, such as monophosphoryl lipid A

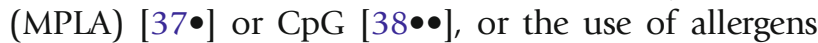
displayed on virus-like particles (VLPs) [39•, 40, 41].

All of the above strategies are based on the dogma that AIT requires the allergen. This dogma has been

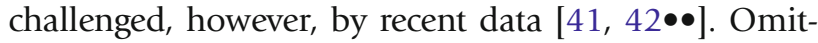
ting the allergen from the vaccine would strike two birds with one stone. First, this would make immunotherapy safer by avoiding allergic adverse events. Second, one vaccine could be used for all allergies. The present review will discuss the scientific rationale behind this strategy and the available clinical data.

\section{Therapy}

\section{Use of VLPs}

VLPs spontaneously assemble upon expression of virus or bacteriophage capsid proteins (Fig. 1). Some of these VLPs, such as RNA phage-derived VLPs, spontaneously package bacterial RNA upon expression. This RNA may be replaced by DNA rich in nonmethylated CpG motifs (CpGs) [43, 44]. VLPs have proven to be safe and well tolerated and are today broadly used for prophylactic

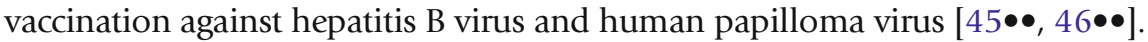
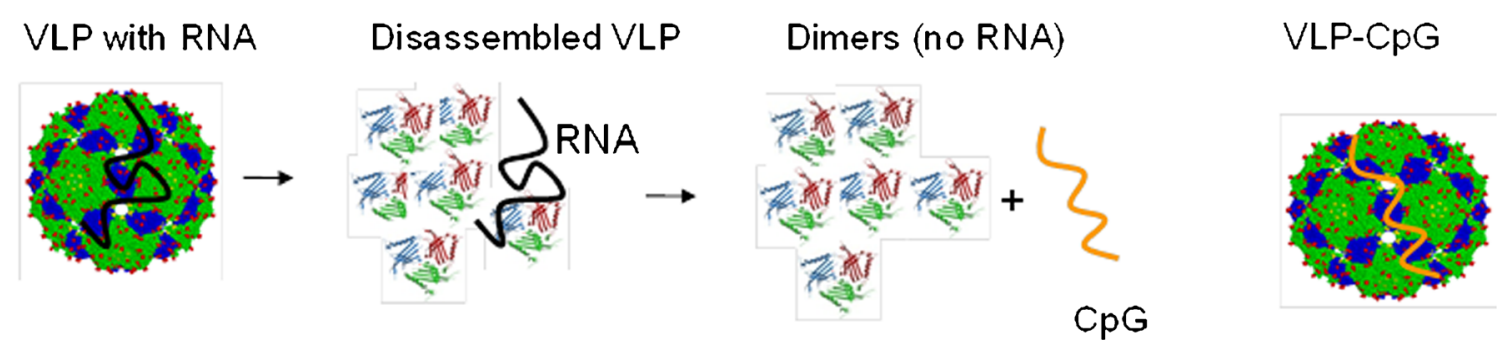

Fig. 1. Loading of virus-like particles (VLPs) with CG motifs (CpGs). In a first step, VLPs are disassembled, the RNA is removed in a second step, and the VLPs are finally reassembled in the presence of CpG G10. This results in VLPs loaded with CpGs. 
VLPs are also currently being evaluated in therapeutic vaccination against cancer and other noncommunicable chronic diseases, as well as infections [47].

Because of their natural function as carriers of genetic information, virus or bacteriophage capsid-derived VLPs can readily be filled with DNA or RNA. VLPs stabilize and protect these molecules from enzymatic degradation by DNAses and RNAses. Bacteriophage-derived VLPs filled with immunostimulatory CpGs have been used to display tumor antigens and were found to efficiently induce tumor antigen-specific cytotoxic CD8 and CD4 T cells in melanoma patients [48-50]. Similar CpGs were successfully used as adjuvants in prophylactic vaccination to enhance B cell responses [51]. Overall, VLP technology bears great potential for delivery of $\mathrm{CpG}$ in cancer, autoimmune disease, and allergies [44]. The present review will focus on clinical experience using bacteriophage VLPs filled with CpGs for treatment of allergic respiratory disease.

\section{Immune responses induced by VLPS}

VLPs can be subcutaneously or intramuscularly injected. Their diameter of approximately $30 \mathrm{~nm}$ facilitates entry into lymphatic vessels and direct drainage into local lymph nodes [52-54]. Once in the lymph node, VLPs are taken up by lymph node resident dendritic cells (DCs). Again, this uptake is enhanced by the size and form of VLPs [55]. VLPs are excellent inducers of CD4 T cells via the major histocompatibility complex (MHC) class II pathway, but also cross presentation on the MHC class I pathway is highly efficient $[56,57]$.

DCs can be subdivided into two main populations. While myeloid DCs (mDCs) produce mainly interleukin (IL)-12, plasmacytoid DCs (pDCs) produce mainly interferon (IFN)- $\alpha$ [58-60]. CpGs are important inducers of cytokines in these cells. There is, however, an important difference between mice and humans. In mice, both pDCs and mDCs express toll-like receptor (TLR)-9, while in humans, only pDCs express TLR9. Hence, IL-12 is hardly induced in humans and the dominant cytokine is usually IFN- $\alpha$ [60, 61]. This has important implications for the type of CpG that may be used for therapy, as outlined below.

Overall, the immune response against VLPs is characterized by immunological properties similar to those seen with live viral vaccines, but, in contrast to the latter, VLPs have the following advantages:

1. The complete lack of genetic information with regard to viral replication enhances safety. In contrast to attenuated vaccines, no reversion to the virulent form is possible.

2. As VLPs assemble spontaneously, they can be produced cheaply in Escherichia coli or yeast, in accordance with Good Manufacturing Practice (GMP) guidelines.

3. The size and form of VLPs enhance lymphatic drainage and uptake by antigen-presenting cells in the local lymph nodes.

4. Immunostimulatory CpGs or RNA can be packaged into VLPs and are stabilized and protected from enzymatic digestion inside the VLPs [44]. Many protein and other antigens can readily be displayed on the surface of VLPs. These antigens can either be genetically fused to the VLP protein, or they can be chemically linked to the surface of the VLP. Hence, VLPs may be used as a display platform to render antigens of choice highly immunogenic. 


\section{CpG motifs}

The human immune system can be activated by pathogen-associated molecular patterns (PAMPs), which are common to nearly all pathogens. These include nonmethylated CG-rich DNA sequences, which are common in the bacterial genome but not in the genome of vertebrates, where these motifs are usually methylated. Numerous such CpGs have been characterized and can be synthesized as oligodeoxynucleotides (ODNs), using either the naturally occurring "phosphodiester" bonding or the more stable "phosphorothioate" bonding in the backbone of the molecule, hence the designation " $\mathrm{C}-\mathrm{p}-\mathrm{G}$ ". CpGs bind to TLR9, which activates (via the adaptor molecule MyD88) the nuclear factor (NF)- $\kappa \mathrm{B}$ pathway, which starts the inflammatory cascade [62].

Three different types of CpGs have been distinguished-namely, A-, B-, and C-type CpGs. Type A CpGs contain their CG motifs in a palindromic sequence, surrounded by guanosines. The backbone of type A CpGs consists of phosphodiester bonds, which are readily digested by DNAses. In contrast, the backbone of type B CpGs consists of phosphorothioate bonds, which are DNAse resistant. Type C CpGs are characterized by phosphorothioate bonds, as well as CG motifs in palindromes on a phosphodiester backbone. These three different types of CpGs differ in their immunological activities. Type A CpGs induce mainly IFN- $\alpha$, whereas type B CpGs are potent activators of B cells but barely induce IFN- $\alpha$. In mice, type B CpGs are potent inducers of IL-12 in mDCs. But, as mentioned above, as human mDCs do not express TLR9, the IL12 response to this type of $\mathrm{CpG}$ is inefficient in humans. In addition, pDCs essentially fail to respond to type B CpGs, as they produce only low levels of IL12 and do not respond with the production of IFN- $\alpha$ to stimulation with this type of CpG. Thus, human DCs respond very poorly to B-type CpGs. Finally, type C CpGs have the characteristics of both A- and B-type CpGs.

While, in mice, TLR9 is expressed in both pDCs and mDCs, in humans, TLR9 is expressed only in pDCs. TLR9 is also expressed in B cells, mast cells, neutrophils, eosinophils, basophils, and keratinocytes [63]. TLR9 is intracellularly located, i.e., within the endosomes, which are accessed by phagocytosed pathogens first. Stimulation of TLR9 polarizes the immune response towards the Thelper (Th)-1 type and stimulates immunoglobulin class switching toward IgG2a in mice [64, 65] and IgG in humans [66]. Th1 cells, as well as IFN- $\alpha$ production, can suppress Th2 cells [67] and downregulate IgE production. TLR stimulation also has direct effects on mast cells, basophils, and eosinophils [68]. The physiological relevance of these interactions is, however, less clear.

\section{Rationale for use of VLPs as vaccines}

The human immune system has evolved to efficiently recognize highly repetitive structures, because such structures are typically found on the 
surfaces of viruses and bacteria. To speed up the antibody response, such repetitive arrays of epitopes can crosslink such large numbers of B cell surface receptors that antibody production is induced even in the absence of $\mathrm{T}$ cell help. Therefore, repetitive antigens, such as those found on the surface of VLPs, are known as "Th-independent antigens" [69••]. In addition, antigen-presenting cells have evolved to efficiently take up particles of viral size and VLP content is scanned by TLRs in the endosomes. The innate humoral immune system has finally also evolved to recognize repetitive structures, enhancing both $\mathrm{B}$ cell activation and uptake/activation of antigen-presenting cells [44].

\section{Clinical trials with CpGs in immunotherapy for allergic rhinitis}

Allergen covalently coupled to CPGs

Allergen conjugated to VLPs filled with RNA

Creticos et al. performed a clinical trial using the major ragweed allergen

Amb a 1 conjugated to a type B CpG-ODN in 25 ragweed-allergic patients [38••]. In this randomized, double-blind, placebo-controlled phase II study, adult patients received a total of six injections at weekly time intervals. The primary endpoint, which was vascular permeability as measured by the serum albumin concentration in nasal lavage, was not significantly ameliorated in this trial. However, clinical symptoms of allergic rhinitis were ameliorated and quality-of-life scores improved already during the first season after treatment. This improvement persisted also in the following pollen season, i.e., 2 years after vaccination. The treatment proved safe and well tolerated, with no severe adverse events. The authors also observed absence of the IgE boost usually observed after the ragweed season in the treatment group. The highly encouraging phase II clinical data could, however, not be reproduced in a larger phase III clinical trial [70]. This may have been due to the fact that the ragweed pollen counts were particularly low in the relevant season and symptoms consequently were very minor also on placebo. On the other hand, use of B-type CpGs, which inefficiently stimulate human DCs, may have resulted in reduced clinical efficacy (Table 1).

We have performed an open-label phase I clinical trial with a house dust mite (HDM) Der p 1-derived peptide of 16 amino acids in length, which was covalently coupled by a chemical linker to bacteriophage Q $\beta$-derived VLPs filled with E. coli-derived RNA ligand for TLR7 and 8. The vaccine was administered three times at 4 -week time intervals. Twenty-four healthy volunteers participated in this study, and antibody titers were followed for 18 months [39•]. The vaccine was well tolerated, and we observed only local reactions at the site of injection. Already 4 weeks after the first injection, we observed a rapid Der p 1specific serum IgM and IgG response. Interestingly, the IgG subclasses were mainly IgG1 und IgG3 - thus those subclasses typically observed after viral infection, rather than the IgG4 response typically observed after conventional AIT. We observed no differences between the 


\begin{tabular}{|c|c|c|c|c|}
\hline Vaccine & Treatment arms & $\begin{array}{l}\text { Patients and } \\
\text { disease }\end{array}$ & Study design & Reference \\
\hline Q $\beta$ VLP coupled to Der & i.m. 50 & $\begin{array}{l}24 \text { volunteers; } \\
\text { healthy }\end{array}$ & $\begin{array}{l}\text { Randomized, } \\
\text { monocentric, } \\
\text { open-label }\end{array}$ & {$[39 \bullet]$} \\
\hline $\mathrm{p}$ & $\mu \mathrm{g} Q \beta$-Der & & & \\
\hline 1-derived peptide (Q $\beta$-Der & $p$ & & & \\
\hline p & $\begin{array}{l}1(n=6), \\
\text { s.c. } 50\end{array}$ & & & \\
\hline $\begin{array}{l}\text { 1). Note that this VLP was } \\
\text { loaded with E.coli RNA }\end{array}$ & $\mu \mathrm{g} Q \beta$-Der & & & \\
\hline & $p$ & & & \\
\hline
\end{tabular}

Allergen admixed to VLPs filled with CPGs

intramuscular and the subcutaneous routes of injection [39•] (Table 1 ). It would be interesting to repeat this study with VLPs loaded with CpGs rather than RNA.

In an additional clinical trial, we investigated the safety and tolerability, as well as the clinical efficacy, of type-A CpGs packed in Q $\beta$-derived VLPs. The CpG-loaded VLPs were mixed with HDM allergens and used as an adjuvant in specific immunotherapy [71] (Table 1). In order to keep the formulation simple, CpG-containing VLPs were simply mixed with a conventional HDM extract. Twenty HDM-allergic patients were included in this openlabel, monocentric clinical trial. The first few injections were performed with the HDM extract only, following the conventional cluster regimen. This short uptitration phase was followed by a total of six weekly injections of HDM extract mixed with VLPs containing CpGs. The clinical endpoints of this trial were conjunctival provocation testing, as well as monitoring of allergic rhinitis and asthma, quality-of-life questionnaires, skin prick tests and antibody measurements. We found a good safety and tolerability profile. Symptoms of allergic rhinitis and asthma were significantly reduced, and allergen-specific IgG was found to increase. Allergen-specific $\mathrm{IgE}$, after an initial rise, was subsequently also found to decrease [71]. We repeated that clinical trial in a double-blind and placebo-controlled manner. In this clinical trial, HDM extract mixed with CpG-containing VLPs was compared with HDM extract alone or with CpG-containing VLPs alone, or with another arm containing only placebo (Senti et al., unpublished). This trial could essentially confirm the results of the open-label study. We were surprised, however, to find that the clinical effects with VLPs filled with 
CpG alone were as good as those obtained when the HDM extract was admixed. These puzzling results were the starting point of a clinical trial program where the allergen was to be omitted from allergen-specific immunotherapy.

In the following clinical trial, we therefore used the same $\mathrm{Q} \beta$-derived VLPs filled with the same type A CpG, named G10. The study was a randomized, double-blind, placebo-controlled phase IIb trial in 299 patients suffering from allergic rhinoconjunctivitis due to HDM allergy $[42 \bullet \bullet]$ (Table 1). Patients received 6-weekly injections either with verum or placebo. The study duration per patient was 9 weeks. The clinical endpoints were the symptom and medication scores and quality-of-life scores, as well as conjunctival provocation testing. The treatment proved to be safe and well tolerated. Symptom and medication scores improved significantly in the high-dose verum group, confirming that treatment with VLPs filled with CpGs alone could ameliorate allergic rhinitis, even without injection of allergen.

\section{Possible mechanisms of immunotherapy without allergens}

Animal models suggest that type-A CpG-induced Th1 responses and IFN- $\alpha$ inhibit Th2 responses. Furthermore, symptom amelioration could also be due to direct effects of CpGs on mast cells, which also express TLR9 [72-74]. CpGs have also been found to change the enzymatic activity of indoleamine 2,3

dioxygenase (IDO), an enzyme known to play an important role in T cell regulation $[75 \bullet]$. Following CpG-induced IFN- $\alpha$ production, the cytokine was found to upregulate IDO in DCs, leading to T cell suppression [76]. This mechanism may explain some of the inflammation-inhibiting effects of CpGs in allergic diseases. On an epidemiological level, the "hygiene hypothesis" supports the notion that bacterial byproducts have inhibitory effects on the development

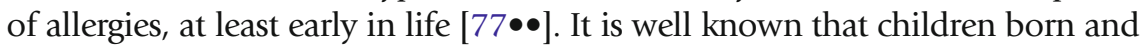
raised on farms have a significantly lower risk of respiratory allergies and asthma. The same is true for children born into households with many children, as well as households with pets, and for children visiting day care centers [78-80]. The persistent protective effect of exposure to bacterial byproducts early in life may be explained by epigenetic modifications [81] or by long-lived Th1 cells, creating a cytokine milieu disfavoring the development of Th2 cells. CpGs have also been found to activate ICOS ligands on pDCs, which represents an important costimulatory molecule for the induction of regulatory $\mathrm{T}$ cells [82].

Last ,but not least, it should not be forgotten that if clinical trials are being performed in HDM allergy, the latter allergens are nearly ubiquitous and present during the entire season. It can therefore not be excluded that the natural exposure to allergen plays a role in the "allergen-free" treatment regimens being discussed.

Thus, treating allergies with CpG-loaded VLPs remains an attractive option and may allow desensitization of a large number of patients in an efficient manner in the absence of risk of anaphylactic reactions. However, there are a number of questions that still need to be resolved, including finding the 
optimal dose and the duration of the therapeutic effect. Further clinical trials are therefore required to elucidate whether "allergen-free" immunotherapy is a valuable long-term treatment option for allergies.

\section{Compliance with Ethics Guidelines}

\section{Conflict of Interest}

Thomas M. Kündig declares that he has no conflict of interest.

Philipp Schendzielorz declares that he has no conflict of interest.

Wolfgang A. Renner declares that he has no conflict of interest.

Gabriela Senti declares that he has no conflict of interest.

Ludger Klimek has board memberships with MEDA, Germany and Novartis, Switzerland; is a consultant to ALK Abelló, Denmark, Allergopharma, Germany, Bionorica, Germany, Boehringer Ingelheim, Germany, GSK, Great Britain, Lofarma, Italy, Novartis, Switzerland, MEDA, Germany, MSD, USA, Phadia Thermofisher, Sweden, and Optima, Germany; has grants/grants pending with ALK Abelló, Denmark, Allergopharma, Germany, Artu-Biologicals, the Netherlands, Bencard, Great Britain, Bionorica, Germany, Biomay, Austria, Cytos, Switzerland, HAL, Netherland, Hartington, Spain, GSK, Great Britain, Leti, Spain, Lofarma, Italy, Novartis, Switzerland, and Roxall, Germany; has received payment for manuscript preparation from MEDA, Germany, Dr. Pfleger, Germany, and Bionorica, Germany; and has received payment for development of educational presentations from ALK Abelló, Denmark, Allergopharma, Germany, Bionorica, Germany, Boehringer Ingelheim, Germany, GSK, Great Britain, Lofarma, Italy, Novartis, Switzerland, MEDA, Germany, MSD, USA, Phadia Thermofisher, Sweden, and Optima, Germany.

Martin F. Bachmann is employed by Cytos Biotechnology and is named as an inventor on numerous patents regarding AIT with VLPs.

\section{Human and Animal Rights and Informed Consent}

This article does not contain any studies with human or animal subjects performed by any of the authors.

Open Access This article is distributed under the terms of the Creative Commons Attribution License which permits any use, distribution, and reproduction in any medium, provided the original author(s) and the source are credited.

\section{References and Recommended Reading}

Papers of particular interest, published recently, have been highlighted as:

- Of importance

$\bullet$ Of major importance

1. Bauchau V, Durham SR. Prevalence and rate of diagnosis of allergic rhinitis in Europe. Eur Respir J. 2004;24:758-64.

2. Bousquet J et al. Allergic Rhinitis and its Impact on Asthma (ARIA) 2008 update (in collaboration with the World Health Organization, GA(2)LEN and AllerGen). Allergy. 2008;63 Suppl 86:8-160.

3. Bousquet J, Lockey R, Malling HJ. Allergen immunotherapy: therapeutic vaccines for allergic diseases. A
WHO position paper. J Allergy Clin Immunol. 1998;102:558-62.

4. Calderon, M.A., et al. Allergen injection immunotherapy for seasonal allergic rhinitis. Cochrane Database Syst Rev CD001936 (2007).

5. Wise SK, Schlosser RJ. Subcutaneous and sublingual immunotherapy for allergic rhinitis: what is the evidence? Am J Rhinol Allergy. 2012;26:1822. 
6. Cox L et al. Allergen immunotherapy: a practice parameter third update. J Allergy Clin Immunol. 2011;127:S1-S55.

7. Cox LS et al. Sublingual immunotherapy: a comprehensive review. J Allergy Clin Immunol. 2006;117:1021-35.

8. Kariyawasam HK, Rotiroti G, Robinson DS. Sublingual immunotherapy in allergic rhinitis: indications, efficacy and safety. Rhinology. 2013;51:9-17.

9. Durham SR et al. Long-term clinical efficacy of grasspollen immunotherapy. N Engl J Med. 1999;341:46875.

10. Eng PA, Reinhold M, Gnehm HP. Long-term efficacy of preseasonal grass pollen immunotherapy in children. Allergy. 2002;57:306-12.

11. Jacobsen L et al. Specific immunotherapy has longterm preventive effect of seasonal and perennial asthma: 10-year follow-up on the PAT study. Allergy. 2007;62:943-8.

12. Moller $\mathrm{C}$ et al. Pollen immunotherapy reduces the development of asthma in children with seasonal rhinoconjunctivitis (the PAT-study). J Allergy Clin Immunol. 2002;109:251-6.

13. Pajno GB, Barberio G, De Luca F, Morabito L, Parmiani $S$. Prevention of new sensitizations in asthmatic children monosensitized to house dust mite by specific immunotherapy. A six-year follow-up study. Clin Exp Allergy. 2001;31:1392-7.

14. Donahue JG, Greineder DK, Connor-Lacke L, Canning CF, Platt R. Utilization and cost of immunotherapy for allergic asthma and rhinitis. Annals Allergy Asthma Immunol. 1999;82:339-47.

15. Hankin CS et al. Allergy immunotherapy among Medicaid-enrolled children with allergic rhinitis: patterns of care, resource use, and costs. J Allergy Clin Immunol. 2008;121:227-32.

16. Szeinbach SL, Williams PB, Kucukarslan S, Elhefni H. Influence of patient care provider on patient health outcomes in allergic rhinitis. Ann Allergy Asthma Immunol. 2005;95:167-74.

17. Winther L, Arnved J, Malling HJ, Nolte H, Mosbech H. Side-effects of allergen-specific immunotherapy: a prospective multi-centre study. Clin Exp Allergy. 2006;36:254-60.

18. Valenta R, Niederberger V. Recombinant allergens for immunotherapy. J Allergy Clin Immunol. 2007;119:826-30.

19. Larche M. Update on the current status of peptide immunotherapy. J Allergy Clin Immunol. 2007;119:906-9.

20. Worm M, Patel D, Creticos PS. Cat peptide antigen desensitisation for treating cat allergic rhinoconjunctivitis. Expert Opin Investig Drugs. 2013;22:1347-57.

21.• Patel D et al. Fel d 1-derived peptide antigen desensitization shows a persistent treatment effect 1 year after the start of dosing: a randomized, placebo-controlled study. J Allergy Clin Immunol. 2013;131(103109):e101-7.
This clinical trial demonstrates that allergen-derived oligopeptides representing CD4 T cell epitopes are sufficient for allergen-specific immunotherapy. These peptides do not bind IgE and therefore no longer cause allergic adverse events.

22.• Senti G et al. Intralymphatic allergen administration renders specific immunotherapy faster and safer: a randomized controlled trial. Proc Natl Acad Sci U S A. 2008;105:17908-12.

This study demonstrates that allergen-specific immunotherapy can be shortened to only three injections if the allergen is delivered to the immune system more efficiently, i.e., by direct injection into a lymph node.

23. Senti G, Johansen P, Kundig TM. Intralymphatic immunotherapy: from the rationale to human applications. Curr Top Microbiol Immunol. 2011;352:71-84.

24. Kundig TM, Johansen P, Bachmann MF, Cardell LO, Senti G. Intralymphatic immunotherapy: time interval between injections is essential. J Allergy Clin Immunol. 2014;133:930-1.

25. Senti G et al. Intralymphatic immunotherapy for cat allergy induces tolerance after only 3 injections. J Allergy Clin Immunol. 2012;129:1290-6.

26. Hylander T, Latif L, Petersson-Westin U, Cardell LO. Intralymphatic allergen-specific immunotherapy: an effective and safe alternative treatment route for polleninduced allergic rhinitis. J Allergy Clin Immunol. 2013;131:412-20.

27. Mondoulet L et al. Epicutaneous immunotherapy (EPIT) blocks the allergic esophago-gastro-enteropathy induced by sustained oral exposure to peanuts in sensitized mice. PLoS One. 2012;7:e31967.

28. Mondoulet L et al. Epicutaneous immunotherapy on intact skin using a new delivery system in a murine model of allergy. Clin Exp Allergy. 2010;40:659-67.

29. Mondoulet L et al. Epicutaneous immunotherapy compared with sublingual immunotherapy in mice sensitized to pollen (Phleum pratense). ISRN Allergy. 2012;2012:375735.

30. Mondoulet L et al. Intact skin and not stripped skin is crucial for the safety and efficacy of peanut epicutaneous immunotherapy (EPIT) in mice. Clin Transl Allergy. 2012;2:22.

31. Mondoulet L et al. Epicutaneous immunotherapy using a new epicutaneous delivery system in mice sensitized to peanuts. Int Arch Allergy Immunol. 2010;154:299-309.

32. Senti G, Freiburghaus AU, Kundig TM. Epicutaneous/ transcutaneous allergen-specific immunotherapy: rationale and clinical trials. Curr Opin Allergy Clin Immunol. 2010;10:582-6.

33. Senti G, von Moos S, Kundig TM. Epicutaneous allergen administration: is this the future of allergenspecific immunotherapy? Allergy. 2011;66:798-809.

34. von Moos $\mathrm{S}$ et al. The contact sensitizer diphenylcyclopropenone has adjuvant properties in mice and potential application in epicutaneous immunotherapy. Allergy. 2012;67:638-46. 
$35 . \bullet$ Senti G et al. Epicutaneous allergen administration as a novel method of allergen-specific immunotherapy. J Allergy Clin Immunol. 2009;124:997-1002.

This is the first double-blind, placebo-controlled trial demonstrating that epicutaneous application of allergen extract can ameliorate allergy symptoms.

36. Senti G et al. Epicutaneous allergen-specific immunotherapy ameliorates grass pollen-induced rhinoconjunctivitis: a double-blind, placebocontrolled dose escalation study. J Allergy Clin Immunol. 2012;129:128-35.

37. Rosewich M, Lee D, Zielen S. Pollinex Quattro: an innovative four injections immunotherapy in allergic rhinitis. Hum Vaccines Immunotherapeutics. 2013;9:1523-31.

Recent review of the clinical data on MPLA used as an adjuvant in allergen-specific immunotherapy.

38.• Creticos PS et al. Immunotherapy with a ragweed-tolllike receptor 9 agonist vaccine for allergic rhinitis. $\mathrm{N}$ Engl J Med. 2006;355:1445-55.

This clinical trial demonstrates that an allergen coupled to CpG represents an interesting therapeutic strategy in allergen-

specific immunotherapy.

39. Kundig TM et al. Der p 1 peptide on virus-like particles is safe and highly immunogenic in healthy adults. J Allergy Clin Immunol. 2006;117:1470-6.

First demonstration that allergens coupled to VLPs are highly immunogenic in humans.

40. Bachmann MF, Jennings GT. Therapeutic vaccines for chronic diseases: successes and technical challenges. Phil Trans R Soc B Biol Sci.

2011;366:2815-22.

41. Klimek L, Schendzielorz P, Mueller P, Saudan P, Willers J. Immunotherapy of allergic rhinitis: new therapeutic opportunities with virus-like particles filled with $\mathrm{CpG}$ motifs. Am J Rhinol Allergy. 2013;27:206-12.

42.•• Klimek L et al. Assessment of clinical efficacy of CYT003-QbG10 in patients with allergic rhinoconjunctivitis: a phase IIb study. Clin Exp Allergy. 2011;41:1305-12.

This is the first study challenging the dogma that AIT requires the allergen.

43. Bachmann MF, Jennings GT. Vaccine delivery: a matter of size, geometry, kinetics and molecular patterns. Nat Rev Immunol. 2010;10:787-96.

44. Jennings GT, Bachmann MF. The coming of age of virus-like particle vaccines. Biol Chem. 2008;389:52136

45.• Garland SM et al. Quadrivalent vaccine against human papillomavirus to prevent anogenital diseases. $\mathrm{N}$ Engl J Med. 2007;356:1928-43.

Landmark study demonstrating that human papilloma virus infection and induction of cancer can be prevented by a VLPbased vaccine.

46.• Paavonen $\mathrm{J}$ et al. Efficacy of a prophylactic adjuvanted bivalent L1 virus-like-particle vaccine against infection with human papillomavirus types 16 and 18 in young women: an interim analysis of a phase III double-blind, randomised controlled trial. Lancet. 2007;369:2161-70. Landmark study demonstrating that human papilloma virus infection and induction of cancer can be prevented by a VLP-based vaccine.

Landmark study demonstrating that human papilloma virus infection and induction of cancer can be prevented by a VLPbased vaccine.

47. Jennings GT, Bachmann MF. Immunodrugs: therapeutic VLP-based vaccines for chronic diseases. Annu Rev Pharmacol Toxicol. 2009;49:303-26.

48. Speiser DE et al. Memory and effector CD8 T-cell responses after nanoparticle vaccination of melanoma patients. J Immunother. 2010;33:848-58.

49. Braun $\mathrm{M}$ et al. Virus-like particles induce robust human T-helper cell responses. Eur J Immunol. 2012;42:33040.

50. Goldinger SM et al. Nano-particle vaccination combined with TLR-7 and -9 ligands triggers memory and effector CD8(+) T-cell responses in melanoma patients. Eur J Immunol. 2012;42:3049-61.

51. Cooper CL et al. Safety and immunogenicity of CPG 7909 injection as an adjuvant to Fluarix influenza vaccine. Vaccine. 2004;22:3136-43.

52. Swartz MA. The physiology of the lymphatic system. Adv Drug Deliv Rev. 2001;50:3-20.

53. Reddy ST, Rehor A, Schmoekel HG, Hubbell JA, Swartz MA. In vivo targeting of dendritic cells in lymph nodes with poly(propylene sulfide) nanoparticles. J Control Release. 2006;112:26-34.

54. Manolova V et al. Nanoparticles target distinct dendritic cell populations according to their size. Eur J Immunol. 2008;38:1404-13.

55. Ahsan F, Rivas IP, Khan MA, Torres Suarez AI. Targeting to macrophages: role of physicochemical properties of particulate carriers-liposomes and microspheres-on the phagocytosis by macrophages. J Control Release. 2002;79:29-40.

56. Yewdell JW. Designing CD8+ T cell vaccines: it's not rocket science (yet). Curr Opin Immunol. 2010;22:402-10.

57. Tewalt EF et al. Viral sequestration of antigen subverts cross presentation to CD8(+) T cells. PLoS Pathog. 2009;5:e1000457.

58. Steinman RM et al. The innate functions of dendritic cells in peripheral lymphoid tissues. Adv Exp Med Biol. 2005;560:83-97.

59. Colonna M, Trinchieri G, Liu YJ. Plasmacytoid dendritic cells in immunity. Nat Immunol. 2004;5:1219-26.

60. Pashine A, Valiante NM, Ulmer JB. Targeting the innate immune response with improved vaccine adjuvants. Nat Med. 2005;11:S63-8.

61. Plotkin SA. Vaccines: past, present and future. Nat Med. 2005;11:S5-S11.

62. Bode C, Zhao G, Steinhagen F, Kinjo T, Klinman DM. CpG DNA as a vaccine adjuvant. Expert Revi Vaccines. 2011;10:499-511.

63. Kumagai Y, Takeuchi O, Akira S. TLR9 as a key receptor for the recognition of DNA. Adv Drug Deliv Rev. 2008;60:795-804. 
64. Jegerlehner A et al. TLR9 signaling in B cells determines class switch recombination to IgG2a. J Immunol. 2007; 178:2415-20.

65. Hou B et al. Selective utilization of toll-like receptor and MyD88 signaling in B cells for enhancement of the antiviral germinal center response. Immunity. 2011;34:375-84.

66. Agrawal S, Gupta S. TLR1/2, TLR7, and TLR9 signals directly activate human peripheral blood naive and memory B cell subsets to produce cytokines, chemokines, and hematopoietic growth factors. J Clin Immunol. 2011;31:89-98.

67. Huber JP, Ramos HJ, Gill MA, Farrar JD. Cutting edge: Type I IFN reverses human Th2 commitment and stability by suppressing GATA3. J Immunol. 2010;185:813-7.

68. Fransson $\mathrm{M}$ et al. Expression of toll-like receptor 9 in nose, peripheral blood and bone marrow during symptomatic allergic rhinitis. Respir Res. 2007;8:17.

$69 . \bullet$ Bachmann MF et al. The influence of antigen organization on B cell responsiveness. Science. $1993 ; 262: 1448-51$

This study demonstrates that repetitive antigen structures can induce B cell responses without $\mathrm{T}$ cell help. This study explains how the immune system can respond to VLPs so rapidly and vigorously, and has laid the basis for this technology. It also explains how $\mathrm{T}$ cell tolerance can be broken.

70. Dynavax. Dynavax Tolamba ${ }^{\mathrm{TM}}$ chamber study misses primary endpoint. (2008). http:// investors.dynavax.com/ secfiling.cfm?filingID=1181431-08-32926. Accessed 16 Nov 2014.

71. Senti G et al. Use of A-type CpG oligodeoxynucleotides as an adjuvant in allergen-specific immunotherapy in humans: a phase I/Ila clinical trial. Clin Exp Allergy. 2009;39:562-70.

72. Hessel EM et al. Immunostimulatory oligonucleotides block allergic airway inflammation by inhibiting Th2 cell activation and IgE-mediated cytokine induction. J Exp Med. 2005;202:1563-73.
73. Jagannathan $\mathrm{M}$ et al. TLR cross-talk specifically regulates cytokine production by B cells from chronic inflammatory disease patients. J Immunol. 2009;183:7461-70.

74. Matsushima H, Yamada N, Matsue H, Shimada S. TLR3-, TLR7-, and TLR9-mediated production of proinflammatory cytokines and chemokines from murine connective tissue type skin-derived mast cells but not from bone marrow-derived mast cells. J Immunol. 2004;173:531-41.

75. Kline JN. Eat dirt: CpG DNA and immunomodulation of asthma. Proc Am Thorac Soc. 2007;4:283-8.

Excellent review on how bacterial products such as CpG can modulate asthma.

76. Mellor AL et al. Cutting edge: CpG oligonucleotides induce splenic CD19+ dendritic cells to acquire potent indoleamine 2,3-dioxygenase-dependent $\mathrm{T}$ cell regulatory functions via IFN type 1 signaling. J Immunol. 2005;175:5601-5.

77.• Strachan DP. Hay fever, hygiene, and household size. BMJ. 1989;299:1259-60.

This study laid the ground for the hygiene hypothesis, explaining why allergies are increasing in the modern industrialized world.

78. Ball TM et al. Siblings, day-care attendance, and the risk of asthma and wheezing during childhood. N Engl J Med. 2000;343:538-43.

79. Braun-Fahrlander $\mathrm{C}$ et al. Environmental exposure to endotoxin and its relation to asthma in school-age children. N Engl J Med. 2002;347:869-77.

80. Riedler J et al. Exposure to farming in early life and development of asthma and allergy: a cross-sectional survey. Lancet. 2001;358:1129-33.

81. Begin P, Nadeau KC. Epigenetic regulation of asthma and allergic disease. Allergy Asthma, Clin Immuno. 2014;10:27.

82. Ito T et al. Plasmacytoid dendritic cells prime IL-10producing $\mathrm{T}$ regulatory cells by inducible costimulator ligand. J Exp Med. 2007;204:105-15. 